felloes of a wheel. This derivation corresponds with Digges' description of the instrument.

E. H. V. Melvill.

203 and 204 New Stock Exchange Buildings,

Johannesburg, Transvaal, September 27.

\section{A Supposed New Mineral.}

A specimen of a mineral, forming portion of a mass stated to have been found in the basalt of $\mathrm{Co}$. Antrim, was recently sent for identification to the office of the Geological Survey of Ireland by Mr. S. B. Wilkinson, the senior geologist, to whom it was handed by the finder. As it presents some peculiar features, and appears to be new to science, we take this opportunity of recording its occurrence. The complete examination of the mineral will necessarily occupy some time.

The mineral strongly resembles cobaltite in appearance. Its lustre is metallic, hardness about six. It breaks with a. surface which under the microscope shows a finely conchoidal structure. When etched with an acid a crystalline structure becomes apparent; it is fusible with difficulty, but in the oxyhydrogen flame it melts without apparent alteration. Heated in a closed tube it does not yield any sublimate.

When the mineral is powdered, or even its surface scratched, it emits an odour like that of acetylene prepared from commercial calcium carbide. Hydrofluoric acid dissolves the mineral, the other acids have little effect upon it, while it is readily decomposed by fusion with the alkaline hydroxides.

A preliminary chemical analysis shows that the mineral is essentially a compound of iron, silicon, and carbon. RICHARD J. MOSS. HENRY J. SeyMour.

Laboratory, Royal Dublin Society, October 20.

\section{The Pitcairn Islanders.}

WHEN reading Mr. M. J. Nicoll's "Three Voyages of a Naturalist" a short time ago, I came across the following passage on p. 2 II in the chapter on Pitcairn Island:-

"The older people, as well as the younger children of Pitcairn, have fair complexions, but the people of from thirty to fifty years of age are quite as dark as the average Polynesian. It appears from this that the Pitcairners resemble their ancestors, the 'Bounty' mutineers, every alternate generation."

It may be remembered that in 1790 nine mutineers, six native men, and twelve native women sailed from Tahiti to Pitcairn; the native women killed the native men, and by 1800 only one British sailor was left, from whom the present inhabitants are descended.

Just before the above extract Mr. Nicoll tells us that "Lord Crawford paid a visit to the two oldest inhabitants ... both of whom are grandchildren of the original mutineers." So we see that the grandchildren and the greatgreat-grandchildren were fair, resembling the British men, while the great-grandchildren were dark, resembling the native women. That is to say, that $F_{2}$ and $F_{4}$ generations resembled the $\sigma^{*} P_{1}$, while $F_{3}$. generation resembled the $\mathrm{O}_{\mathrm{i}} \mathrm{P}_{1}$.

These facts struck me as being particularly interesting, as experiments of this nature in human heredity are difficult to obtain. Perhaps some "Mendelist" may be able to use or explain them.

Clare College, Cambridge, October 14.

\section{The Auroral Display of October 18.}

I was very much interested in Mr. Harcourt-Bath's letter describing an auroral display which he saw from the Cotteswold Hills.

From West Kirby Hill, on the Wirral, I noticed a luminous band low down on the horizon, with upward streamers and " a detached red, cloud-like portion" rather north of west.

$$
\text { No. } 2087 \text {, vOL. 81] }
$$

What struck my attention, however, was that behind this red patch there were dark clouds, at no great altitude, faintly illuminated on the underside by the aurora.

As the red colour outlasted the streamers by several minutes, I was brought to the conclusion that it was independent of the auroral display.

However, in view of Mr. Harcourt-Bath's letter, I am led to ask you if observers have ever thought that an aurora could be comparatively close to the earth, and not of necessity in the "highly rarefied layers of the air"?

$$
\text { “ Nunclose," West Kirby, Cheshire. }
$$

ERNest J. Baty.

Ir may interest Mr. Harcourt-Bath to know that the auroral display of October i 8 was strikingly visible at Dudley. At 9.15 p.m. there were six or more broad beams of white light of unequal lengths and widths. These sprang normally from a broad circular arc resembling a "Milky Way "in luminosity and a broad rainbow in shape and size.

The central vertical beam was the brightest, widest, and longest, extending vertically about $45^{\circ}$, but not terminating definitely; it was about $10^{\circ} \mathrm{W}$. of $\mathrm{N}$.

The broad arched base appeared to cross through Ursa Major, the vertex being about $20^{\circ}$ above the horizon, and was not uniformly bright. About 9.30 p.m. the left-hand (W. of N.) half of the base became a soft violet light; the right-hand portion remained white, but grew fainter.

14 Park Road, Dudley, October 26. W. Austin Morley.

\section{The Occurrence in India of the Pappataci Fly (Phlebo- tomus papatasii).}

THE rôle nowadays assigned to Phlebotomus papatasii in the transmission of a certain type of fever (see "Das Pappatacifieber," 1909, by Drs. Doerr, Franz and Taussig) makes the geographical distribution: of this little fly a matter of practical importance. It. is therefore interesting to note that this species is comman in certain parts of northern India. Some time ago Mr. F. M. Howlett, second imperial entomologist, sent me specimens from Rawalpindi, in the Punjab, and Pusa, in Bihar, which I identified as belonging to a species allied to $P$. papatasii. Through the kindness of Dr. J. H. Ashworth I have now been able to compare some of these specimens with European examples of $P$. papatasii in the zoological laboratory of the University of Edinburgh. 1 can find no difference except that the Indian specimens are perhaps slightly smaller than the European ones. The former agree as regards venation, genitalia, \&c., with Grassi's beautiful figures ("Ricerche sui Flebotomi," I907).

In addition to $P$. papatasii, six Indian species of Phlebotomus are now represented in the collection of the Indian Museum. They will be fully described shortly.

N. Annandale.

\section{The Mansfield Automatic Water-finder.}

With reference to Mr. A. A. Campbell Swinton's letter in regard to Mansfield's water-finder, which appears in NATURE of October I4, it may be of interest to state that I made inquiries from Messrs. Mansfield and Co. in May, 1908 , asking for the names of the "leading scientists and engineers" who, as they stated, "vouched for the successful application of the invention"; they did not send me any names, but allowed a friend of mine in Liverpool to call to see the documents. One was from an architect in Liverpool, another from a firm of well-borers, and there were some foreign ones, but none were produced that were signed by persons whom I should describe as "leading scientists and engineers."

I may add that I expressed my willingness to test their instrument, but one was not placed at my disposal.

Merchant Venturers' Technical College, Bristol, J. WERTHEIMER.

October 20. 